\title{
Abrasive Waterjet Machining-A State of Art
}

\author{
P. P. Badgujar ${ }^{1}$, M.G.Rathi ${ }^{2}$ \\ ${ }^{I} P G$ Student, Government College of Engineering, Aurangabad, MS, India \\ ${ }^{2}$ Assistant Professor, Government College of Engineering, Aurangabad, MS, India
}

\begin{abstract}
With the advent of newer materials and intricate shapes of components, unconventional methods of material removal have been developed. Abrasive waterjet machining (AWJM) is one of such processes of material removal. This paper briefly describes the basic features of AWJM, such as, its mechanism of material removal, advantages, disadvantages and application possibilities.
\end{abstract}

Keywords: AWJM, Applications, Advantages, Disadvantages

\section{Introduction}

The principle of rain-erosion phenomenon occurring on high speed aircrafts is well-known and is utilized in high pressure jet -cutting where a high pressure jet of small diameter is directed at a target material at a high velocity.

Abrasive waterjet cutting (also called Abrasive waterjet machining or AWJM) is similar to laser beam machining and electron-beam machining in one respect. The similarity lies in concentrating a given amount of energy into a small point to cause material removal.

Abrasive waterjet cutting involves using an extremely fine jet of water travelling at high velocity, into which an abrasive material is mixed for cutting hard materials such as granite and titanium. This process makes a very fine cut into the material, known as a kerf.

The kinetic energy possessed by a jet increases with the velocity. Hence in precision jet cutting with small diameter jets, though the mass flow rate is reduced, the kinetic energy possessed by the jet increases with the increase in velocity imparted by high pressure. A Schematic Illustration of the Experimental Set-Up of AWJM is shown in Figure 1.

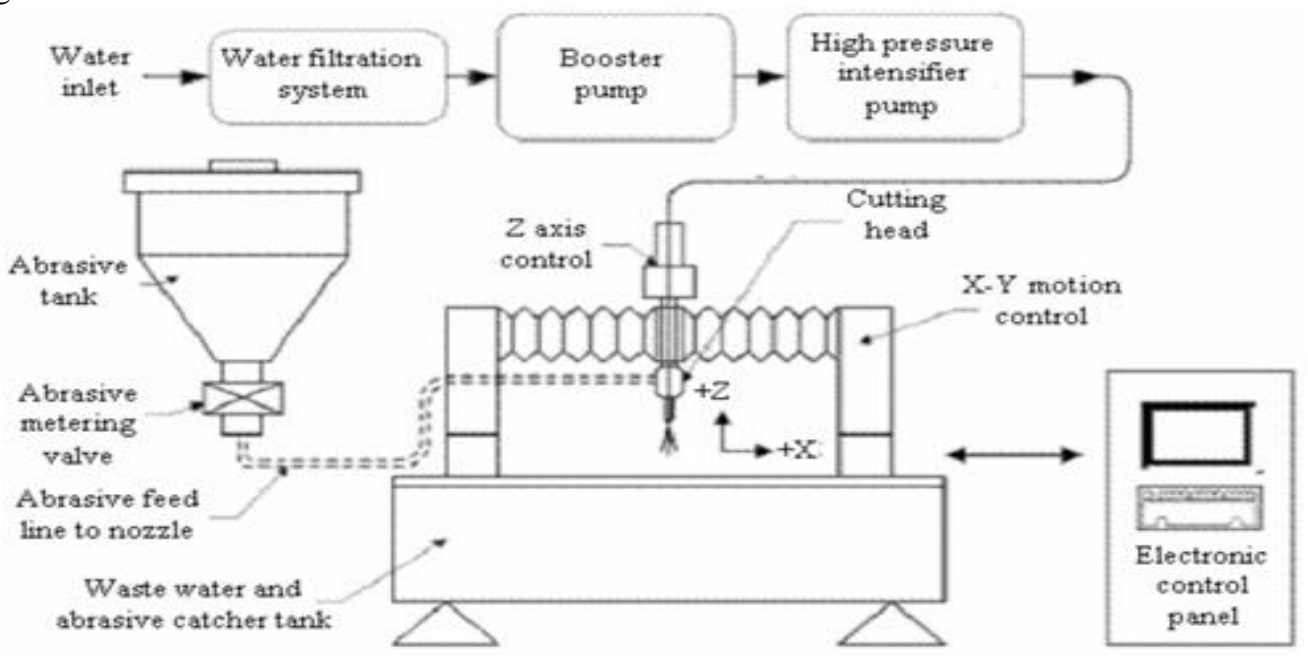

Figure 1 A Schematic Illustration of the Experimental Set-Up of AWJM

When a high velocity water jet is directed at a target in such a way that on striking the surface, the jet velocity is virtually reduced to zero, most of the kinetic energy possessed by the jet is converted into pressure energy. Infact, in the first few milliseconds, after the initial impact the transient pressure generated may be as high as three times the normal stagnation pressure.

The mechanism of jet-cutting is very complex. Material removal is done mechanically by erosion caused due to localized compressive failure which occurs when the local fluid pressure exceeds the ultimate compressive strength of the target material.

When a jet impinges a flat plate at right angles, the fluid spreads out radially over the plate from the centre of impact. The initial velocity of the outward flowing liquid is much higher than the impact velocity. The jet 
produces a shallow indentation on the surface of ductile materials and a ring fracture in brittle materials. The radial flow of liquid across the surface leads to erosive shearing along the edges of the deformed area. Even the smallest surface discontinuities act as nuclei for erosion pits. In ductile materials, surface depressions are eroded by the shearing action of the surface flow. The failure in brittle materials is by fracture where as that in high strength alloys are probably due to fatigue.
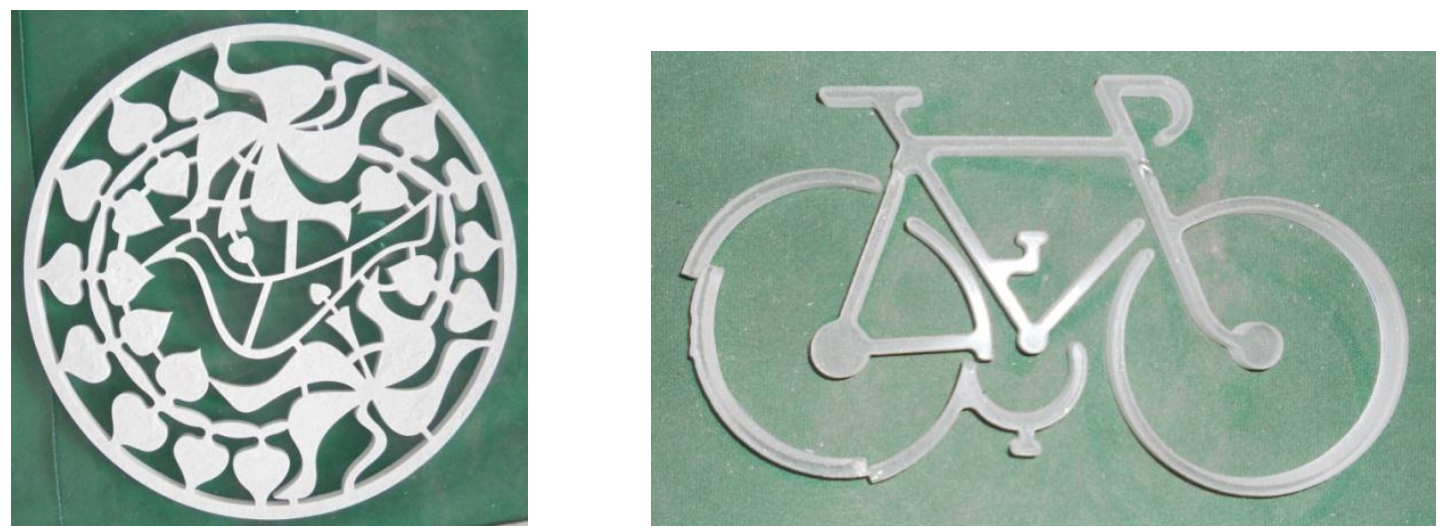

Figure 2 Abrasive Waterjet Machined Workpiece

When quality cutting is not involved, other mechanisms contribute, such as spelling caused by stress waves and the effect of stagnation pressure caused by the cutting fluid penetrating the cracks and pores. Some researchers feel that cavitation also plays a role in eroding the target material; it is known that cavitations collapse can give rise to pressures capable of eroding the strongest solids.

This technology has found extensive applications in industry, particularly in contouring or profile cutting and in processing difficult-to-cut materials such as ceramics and marbles, and layered composites (Figure 2).

\section{Process Parameters}

For successful utilization of AWJM process, it is necessary to analyze the following process criteria:

1. Material removal rate (MRR)

2. Shape and finish of the work piece

3. Wear rate of the nozzle. (Since the nozzle is costly item in the set-up requiring replacement).

Generally, all the involved parameters can be classified into two categories: the input parameters or independent parameters and output parameters or dependent parameters.

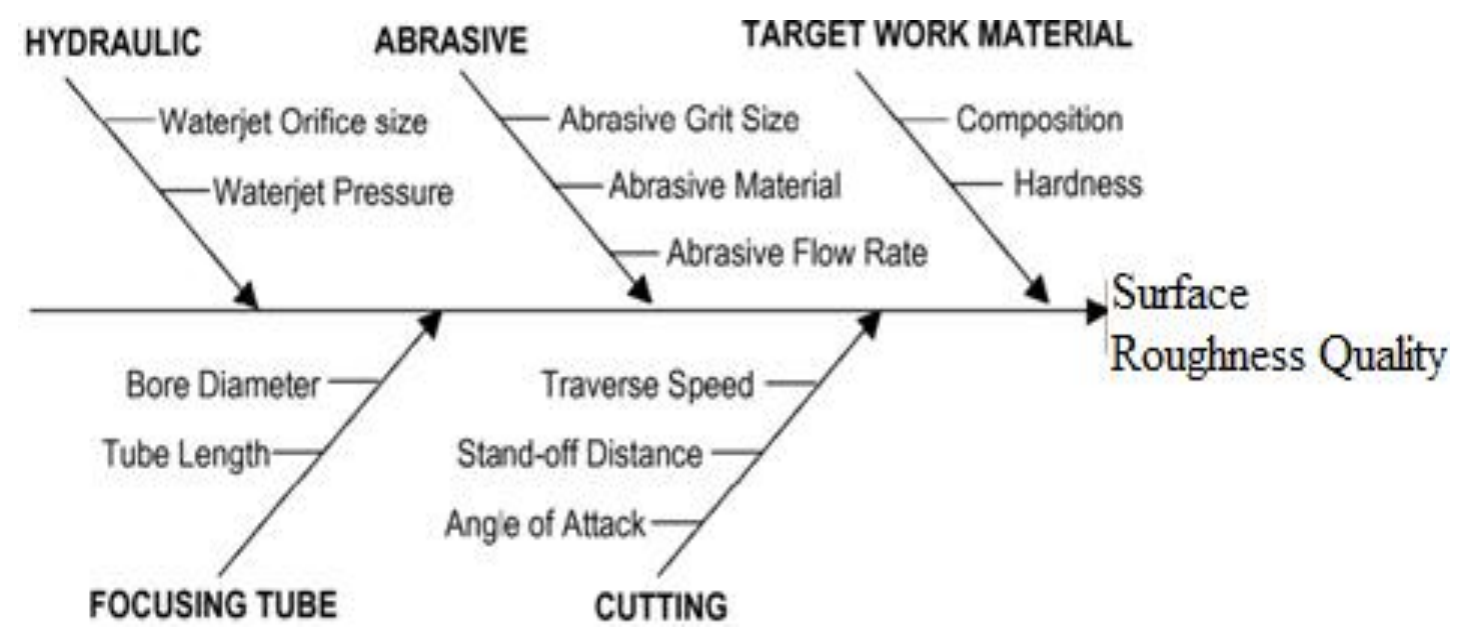

Figure 3 Process Parameters Influencing the AWJ Cutting Process

These parameters are further summarized these parameters into different types in each category as follows:

- Input parameters: Hydraulic parameters: water pressure and waterjet diameter.

- Cutting parameters: Nozzles traverse speed, number of passes, standoff distance and impact angle;

- Mixing and acceleration parameters: nozzle diameter and nozzle length; 
- Abrasive parameters: abrasive mass flow rate, abrasive particle diameter, abrasive particle size distribution, abrasive particle shape and abrasive particle hardness.

- Target material parameters: fracture strength, flow stress, hardness and ductility.

- Output parameters: Depth of cut and smooth depth of cut.

These criteria are greatly influenced by process parameters, such as mass flow rate, velocity of the jet (hence pressure), nozzle diameter and design, standoff distance, feed rate and depth of cut, and the properties of the material being cut.

The general domain of parameters in entrained type AWJ machining system is given below:

Table 01 parameters of AWJM

\begin{tabular}{|c|l|l|}
\hline Sr. No. & \multicolumn{1}{|c|}{ Parameter } & \multicolumn{1}{c|}{ Range } \\
\hline 1 & Water orifice diameter & 0.1 to $0.3 \mathrm{~mm}$ \\
\hline 2 & Focusing tube diameter & 0.8 to $2.4 \mathrm{~mm}$ \\
\hline 3 & Angle of impact & $60^{0}$ to $90^{0}$ \\
\hline 4 & Depth of Cut & $1 \mathrm{~mm}$ to $250 \mathrm{~mm}$ \\
\hline
\end{tabular}

\section{Advantages of AWJM}

Advantages of abrasive waterjet machining are as follows.

1. Water is cheap, non-toxic, readily available, and can be disposed easily.

2. The jet approaches the ideal single point tool. This facilitates designing an efficient automated system.

3. Any contour can be cut and the process gives a clean cut (Figure 2). Accurate cutting enables intricate shapes including sharp corners. Further, the operation is possible in both horizontal and vertical positions.

4. The cut does not have to start from the edge, i.e., no pilot hole is necessary when cutting in the middle of a sheet.

5. Even if you already have a plasma, laser or gas cutting machine, waterjet makes an ideal partner to these processes, increasing the range of materials you can cut, providing superior quality on high finish materials and extending the thickness range you can cut with conventional materials such as steel.

6. A very narrow cut in some materials reduces wastage and lowers cost.

7. The method does not generate heat. Hence there is no possibility of rewelding of the edges of lamination being stack-cut. This occurs frequently in cutting plastics with conventional methods.

8. With no heat generation, there is no thermal degradation of the work-material.

9. Fire hazards are reduced; hence the process is suitable for explosive environments.

10. Blade clogging is avoided. This occurs when cutting sticky materials mechanically.

11. Less moving parts and hence less maintenance is required.

12. Cutting forces are in a single direction. Negligible lateral forces permit cuts close to the edge.

13. Dustless atmosphere- this is particularly advantageous for cutting asbestos and glass fiber insulations which produce dust.

\section{The Advantages of AWJM Compared with other Machining Processes}

A. Advantages of AWJM compared with Lasers Beam Machining (LBM)

Laser cutting involves using a laser focused on material to melt, burn, or vaporize the material. The laser can be a gas laser (such as $\mathrm{CO} 2$ ) or a solid-state laser. The laser beam can be static, and the material moves infront of the laser, or the laser can itself be moved across the material. When the laser moves across the material, additional optics are required as the distance from the emitting end of the laser changes. Lasers have the advantage over traditional machining methods that the laser never touches the material (avoiding contamination) and the heat-affected zone is relatively small.

When compared with other LBM, abrasive waterjet technology offers the following advantages:

1. Can work on more materials: AWJM can machine reflective materials that lasers cannot, such as copper and aluminum. AWJM cut a wide range of material with no changes in setup required. Also, materials which are heat-sensitive can be cut using AWJM.

2. No heat-affected zone (HAZ) with AWJM: AWJM cutting does not produce heat. There is no heataffected zone (HAZ) or thermal distortion, which can occur with lasers. AWJM does not change the properties of the material.

3. AWJM are more environmentally friendly: Abrasive Waterjet typically use garnet as the abrasive 
material. Garnet is a non-reactive mineral that is biologically inert. The only issue with water jet is when you are cutting a material that is potentially hazardous (such as lead), small pieces of the material will be abraded and mix with the spent garnet.

4. Abrasive waterjet is safer: There are no fumes, such as vaporized metal, and no risk of fires. The distance between the end of the water jet nozzle and the material is typically very small, although caution is needed when the water jet nozzle is raised.

5. Uniformity of material not important: With lasers, the material needs to be relatively uniform. In particular, when cutting over uneven surfaces, the laser can lose its focus and cutting power. A water jet will retain much of its cutting power over uneven material. Although the material may deflect the cutting stream, it typically has a negligible effect.

6. Lower capital equipment costs: The cost of an AWJ machine is generally much lower than that of a laser. For the price of a laser, you can purchase several water jet machining centers.

7. Better tolerances on thicker parts: Water jet offer better tolerances on parts thicker than $0.5^{\prime \prime}(12 \mathrm{~mm})$. For thinner parts, both water jet and lasers offer comparable tolerances.

8. Abrasive Waterjet can machine thicker materials: How thick you can cut is a function of how long you are willing to wait. Water jets easily handle 2" $(5 \mathrm{~cm})$ steel and 3" $(7.6 \mathrm{~cm})$. Although some people have used water jet at thicknesses of up to $10^{\prime \prime}(25 \mathrm{~cm})$ in steel, it is difficult to maintain precision in materials thicker than $2 "$ (5 cm). Lasers seem to have a maximum practical cutting thickness of 0.5 " (12 mm) to $0.75^{\prime \prime}(19 \mathrm{~mm})$.

9. Simpler maintenance: Maintenance of a water jet is simpler than that of a laser.

10. Simpler operation: Water jet are computer controlled, so that the operator does not have to be highly skilled and trained.

11. Better edge finish: Material cut by abrasive waterjet have a fine, sand-blasted surface because of the way the material was abraded, which makes it easier to make a high-quality weld. Material cut by laser tends to have a rougher, scaly edge, which may require additional machining operations to clean up.

\section{B. Advantages of AWJM compared with EDM}

EDM stands for Electrical Discharge Machining and is used to machine electrically conductive materials, such as steel and titanium. An electrical arc rapidly discharges between an electrode and the work piece material. The series of arcs removes metal by melting it and vaporizing it, essentially eroding the metal using electricity. The particles are flushed away by a continuously circulating non-conducting fluid, such as deionized water or kerosene. EDM can create intricate shapes in hard materials that are difficult to machine using traditional methods.

Electrical discharge machining is a non conventional metal removal process as well as one of the best manufacturing processes suitable for producing jigs, fixtures and dies. Among other, the machine is able to cut a workpiece having oblique and taper shape.

When compared with other EDM, abrasive waterjet technology offers the following advantages:

1. Can work on more materials: Abrasive Waterjet can machine non-conductive materials that EDM cannot, such as glass, wood, plastic, and ceramic. There is almost no limit to the type of materials that can be machined with AWJM.

2. Uniformity of material not important: A AWJM will retain much of its cutting power over uneven material. Although the material may deflect the cutting stream, it typically has a negligible effect. Such material aberrations would cause wire EDM to lose flushing.

3. Water jet make their own pierce holes: Some types of EDM, such as wire-cut EDM, a hole needs to be first made in the material, which has to be done in a separate process. Water jet can pierce the material, requiring no additional fixturing or machining.

4. No heat-affected zone (HAZ) with AWJM: AWJ cutting does not produce heat. There is no heat-affected zone (HAZ) or thermal distortion, which can occur with EDM. Water jet does not change the properties of the material.

5. Abrasive waterjet require less setup: Most of the fixturing with water jet is weighing down the material so that it does not shift in the water tank. The fixturing needs to withstand forces of pounds and does not need to be elaborate or precise.

6. Make bigger parts: The size of the part created with an AWJM is limited by the size of the material. In setups where the material passes underneath the water jet, the finished part size can be huge. Even with an X-Y table setup, part sizes can be quite large.

\section{Advantages of AWJM compared with Plasma Arc Machining}

The clearest advantage that AWJM have as compared with plasma cutting is that water jets operate at much lower temperatures. During piercing, the temperature of the material may rise as high as $120^{\circ} \mathrm{F}\left(50^{\circ} \mathrm{C}\right)$, but 
cutting typically happens at room temperature. The presence of the catch tank (a large tank full of waste water) helps to moderate the temperature as well. This lower temperature means there is no Heat Affected Zone when material is cut with a AWJM.

AWJM also can cut materials that don't easily melt or that are destroyed by melting. Water jets are also more precise than plasma cutting.

Plasma cutting is typically faster than AWJM, particularly with very thick metal. Plasma torches can pierce and cut steel up to $12 "(30 \mathrm{~cm})$ thick.

\section{Advantages of AWJM compared with Plasma Flame Cutting}

While flame cutting can work only with iron or steel, water jet can machine many different types of materials, both metal and non-metallic. AWJM also do not appreciably heat up the material they cut--during piercing, temperatures may rise to $120^{\circ} \mathrm{F}\left(50^{\circ} \mathrm{C}\right)$, but during cutting the material is heated only a degree or two.

The edge finish created with a AWJM is smooth, similar to a sandblasted finish, rather than the rough edges left by flame cutting. AWJM are more precise than flame cutting and have a much smaller kerf as less material is removed (particularly important when cutting expensive material).

Flame cutting can be faster than water jet, especially when done using a multi-torch cutting machine, and as a result, is cheaper than water jet cutting.

\section{E. Advantages of AWJM compared with Milling}

Although mills cut faster, in most cases, than water jet, the setup and fixturing with water jet is much simpler. Setup with water jet is typically a matter of just loading the part- drawing into the controller software, setting the material thickness and beginning machining. Similarly, fixturing is mostly a matter of weighing down the material so that it doesn't move on the table during machining. Clean-up on a water jet is also faster and simpler. As a result, overall, a water jet can have a greater throughput than a mill on similar parts.

Water jet can also machine almost any material, including brittle materials, pre-hardened materials, and otherwise difficult materials such as Titanium, Hastalloy, Inconel, SS 304, and hardened tool steel.

With a water jet, there is also no tool changing. The water jet nozzle is the only tool used, and it is used for all the different types of materials. There is also less wear on tools, especially in harder materials, because the cutting action of the water jet is the stream of water and abrasive. While there is wear on the mixing tube and high-pressure water components, this wear tends to be constant with time, and doesn't change with different materials.

Water jets are frequently used for complimenting or replacing milling operations. They are used for roughing out parts prior to milling, for replacing milling entirely, or for providing secondary machining on parts that just came off the mill. For this reason, many traditional machine shops are adding water jet capability to provide a competitive edge.

\section{Disadvantages of AWJM}

One of the main disadvantages of waterjet cutting is that a limited number of materials can be cut economically. While it is possible to cut tool steels, and other hard materials, the cutting rate has to be greatly reduced, and the time to cut a part can be very long. Because of this, waterjet cutting can be very costly and outweigh the advantages.

Another disadvantage is that very thick parts cannot be cut with AWJM and still hold dimensional accuracy. If the part is too thick, the jet may dissipate some, and cause it to cut on a diagonal, or to have a wider cut at the bottom of the part than the top. It can also cause a rough wave pattern on the cut surface.

Taper is also a problem with AWJM in very thick materials. Taper is when the jet exits the part at a different angle than it enters the part, and can cause dimensional inaccuracy. Decreasing the speed of the head may reduce this, although it can still be a problem.

AWJM is very expensive process. It is not suitable for mass production because of high maintenance requirements. Flaring can become large.

\section{Applications}

The potential applications of AWJM are numerous. Because of the technical and economic performance of abrasive waterjet, many industries could immediately benefit from this new technology. Over the last decades, AWJM has been found to be widely used in various industries, including manufacturing industry, civil and construction industry, coal mining industry, food processing industry, oil and gas industry, electronic industry and cleaning industry.

Abrasive waterjet cutting is highly used in aerospace, automotive and electronics industries. In aerospace industries, parts such as titanium bodies for military aircrafts, engine components (aluminium, titanium, heat resistant alloys, stainless steel), aluminium body parts and interior cabin parts are made using abrasive water jet 
cutting. AWJM has been particularly used in cutting "difficult-to-cut" materials.

In automotive industries, parts like interior trim (head liners, trunk liners, door panels) and fibre glass body components and bumpers are made by this process. Similarly, in electronics industries, circuit boards and cable stripping are made by abrasive water jet cutting.

In the oil and gas industry, a ship can be equipped with an AWJ cutting system for offshore work. Some examples of what an AWJ cutting system can offer are casing cutting for decommissioning of oil wells, rescue operations, platform cutting and repair, underwater construction and pipe cutting.

The coal mining industry can benefit from AWJ cutting by being able to safely cut metal structures in the potentially explosive environment underground. Coal picks can be replaced with abrasive jets for high productivity.

In the construction industry, in addition to cutting and scarifying for reinforced concretes, AWJ could perform several other useful functions. For example, it could be used to sandblast and cut corroded rebar, or it can drill holes for bolting posts. It is also often used in road and bridge repair, underground work and pile cutting.

In food industry, waterjet cutting can be used for food preparation. The cutting of certain foods such as bread and trimming fat from meats can also be easily done with it. Since the waterjet exerts such a small force on the food, it does not crush it, and with a small kerf width, very little is wasted.

\section{Conclusions}

A variety of materials can be cut by AWJM process. AWJM is a safer and more effective tool for quality cutting. This paper is use to comparative study of AWJM with other traditional and non traditional machining processes. In this paper application, advantages and disadvantage of AWJM are listed.

\section{References}

[1] P.K. Ray, Water Jet Machining-A State of Art, Journal of the Institution of Engineers (I) vol. 63, pt. ME 3 (1982) UDC 621-16/17:621/621.9 108-111

[2] Module 9, lesson 37, non-conventional machining, version 2 ME, IIT Kharagpur.

[3] http://www.wardjet.com/waterjet-university.html

[4] http://waterjets.org/index.php?option=com_content\&task=section\&id=4\&Itemid=43

[5] http://lyle.smu.edurcamresearchwaterjetwj2.html updated on 8th December 2009.

[6] P.K. Mishra, Non conventional Machining, Narosa Publishing House, third reprint -20

[7] M. Chithirai Pon Selvan* and Dr. N. Mohana Sundara Raju, Analysis of surface roughness in abrasive waterjet cutting of cast iron, International Journal of Science, Environment and Technology, Vol. 1, No 3, 2012, 174 - 182 